\title{
Validation of the local thermodynamic equilibrium at a local current concentration area of the positive pulsed surface discharge plasma on water
}

Tomohiro Furusato $^{1 *}$, Kazushi Oura ${ }^{1}$, Yoshinobu Matsuda ${ }^{1}$, Mitsuru Sasaki $^{2}$, Yuki Inada ${ }^{3}$ and Takahiko Yamashita ${ }^{1}$

${ }^{1}$ Graduate School of Engineering, Nagasaki University, Nagasaki 852-8521, Japan

${ }_{2}^{2}$ Institute of Pulsed Power Science, Kumamoto University, Kumamoto 860-8555, Japan

${ }^{3}$ Division of Mathematics, Electronics and Information Sciences, Saitama University,

Saitama 338-8570, Japan

E-mail: t-furusato@nagasaki-u.ac.jp

The pulsed surface discharge on water has been focused as water purification technology and material synthesis method. The contribution of this study is to clarify the plasma state of a positive pulsed surface discharge on water. Although the pulse width of the current dramatically decreases with the applied voltage ranging from 10 to $20 \mathrm{kV}$ under the conductivity of water of $1 \mathrm{mS} / \mathrm{cm}$ and water depth of $2 \mathrm{~mm}$, the plasma state in the vicinity of the needle electrode is local thermodynamic equilibrium (LTE) state. The validation of the LTE was performed by McWhirter criterion. On the other hand, the propagating discharge along the water surface is supposed to be the non-LTE state. Consequently, the pulsed surface discharge on water is mixed states of LTE and non-LTE. 


\section{Introduction}

Pulsed surface discharge on water has been studied aiming water purifications and material synthesis for several decades. ${ }^{1-10)}$ Understanding of the plasma behavior is important to control the plasma chemical reactions; however, the plasma formation on the water surface is not simple because the plasma parameters drastically change by experimental conditions, e.g., water conductivity and water depth. The impedance of water solution varies by the water conductivity and the water depth and has a significant impact on the formation of the plasma in contact with the water. In addition, the impedance of water continues to vary while propagating a surface discharge because the discharge contact area also varies with the propagating discharge. ${ }^{11,12)}$ The effect of the experimental condition on the discharge contact region with water was verified under a constant condition of applied voltage and water depth: 1) the discharge branching pattern on water changes as a function of water conductivity; ${ }^{13,14)}$ 2) the shape of the ground electrode immersed in water affects the surface discharge region on water. ${ }^{15)}$ On the other hand, the pulse current waveform is one of the indicators of plasma behavior. The magnitude and width of pulse current through the plasma and water strongly depends on the impedance of water and a capacitance of a pulsed power generator. Although the above viewpoints are important to understand the plasma behavior, few studies have focused on the changes in the plasma owing to the experimental conditions.

The pulsed surface discharge on water cathode has been reported under several applied voltage and current as follows. P. Bruggeman et al. reported the time-dependent of emission of the molecular and atom with a few tens of nanosecond square-wave voltage pulse of $4 \mathrm{kV}$ and the linear increase current reaching 4 A. ${ }^{16)}$ S. Kanazawa et al. observed the ground-state $\mathrm{OH}$ radicals by laser-induced fluorescence with the peak voltage of $20 \mathrm{kV}$ and the current of 10 A. ${ }^{17)} \mathrm{P}$. Lukes et al. studied the oxidation processes in water originated from the surface discharge with the peak voltage of $45 \mathrm{kV}$ and current of $12 \mathrm{~A} .{ }^{18)} \mathrm{N}$. Midi et al. measured the current distribution in water owing to the spark on water by applying a standard lightning impulse voltage ranging from 15 to $20 \mathrm{kV}$ and current ranging from 40 to $120 \mathrm{~A} .{ }^{19)} \mathrm{Y}$. Akishev et al. demonstrated the control of the branching of the surface discharge on water and trajectory of the discharge propagation by applying the voltage of $23 \mathrm{kV}$ and the current of $20 \mathrm{~A}^{20)}$ As stated above, the pulsed surface discharge on water has been studied quite different conditions.

We studied the behavior of the pulsed surface discharge plasma on water against water cathode by varying the applied voltage. A simple pulsed power circuit that consists of a DC power supply, a capacitor, and a self-spark gap switch was used to verify the complex 
phenomena of the discharge. We discuss the local thermodynamic equilibrium of the plasma using the plasma temperature and electron density by taking into account the current, applied voltage, and pulse width.

\section{Experimental setup}

Figures 1 (a) and (b) show the experimental setup and a discharge observation system. The discharge plasma was generated under atmospheric air. The capacitor $(2 \mathrm{nF})$ was connected in parallel to the needle-to-plane electrode. The pulsed voltage was applied to the tungsten needle electrode when the self-spark gap switch was turned on. The gap distance between the needle electrode and the water surface was approximately $1 \mathrm{~mm}$. The ground electrode was installed on the bottom of a plastic cylindrical container filled with water. The diameter of the cylindrical container is $138 \mathrm{~mm}$. The applied voltage was varied by adjusting the gap length of the switch. The voltage at the needle electrode was measured by a high voltage probe (Iwatsu Co. Ltd., Tokyo, Japan, HV-P30). A current monitor (Pearson electronics Co. Ltd., Palo Alto, CA, USA, model 4100) was set at the ground side of the reactor to measure the current. The conductivity of water was set to $1 \mathrm{mS} / \mathrm{cm}$ by dissolving potassium chloride $(\mathrm{KCl})$. The spectroscopic measurement was performed by a CCD multichannel spectrometer (Glacier X, B\&W Tek. Inc.). A radiance calibration of the spectrometer was done in advance. The emission from the discharge channel immediately below the needle tip was measured by a collimating lens as shown in Fig. 1 (b). The emissions of the pulsed discharge which is automatically generated by the self-spark gap switch were accumulated to the spectrometer within the exposure time of $15 \mathrm{~s}$. The measurement region of the plasma depending on the collimating lens was $\phi=8 \mathrm{~mm}$. Figure 2 shows the example of the top view of the singleshot surface discharge on water $(20 \mathrm{kV}$ and water depth of $2 \mathrm{~mm})$. The radial discharge plasma grew along the water surface centering just below the needle tip. The measuring region of the plasma was almost around the needle tip as can be seen in the scale of Fig. 2. The maximum discharge length from the needle varied ranging from approximately 10 to 20 $\mathrm{mm}$ in this study.

\section{Results and discussion}

\subsection{Voltage and current waveforms}

Figure 3 shows typical voltage/current waveforms under the water depth of $2 \mathrm{~mm}$. A large pulse current flows via plasma channel and water after the self-spark gap switch and the gap between the needle and water turn on. The plasma behavior is profoundly affected by the 
magnitude of the current and its duration time. The detailed plasma behavior is discussed in Sect. 3.3. Figure 4 shows the peak value of current and its FWHM (Full Width at Half Maximum) as a function of the applied voltage. The error bar indicates a standard deviation. The peak current linearly increased with the voltage. Meanwhile, the FWHM of the current dramatically decreased with the applied voltage. The magnitude of the current is important in understanding the decay of the voltage/current waveforms. According to our previous study, the field strength along the water surface is proportional to the current on the basis of an electromagnetic theory. ${ }^{21)}$ The large current with high voltage application leads to the strong intensity field along the water surface. As a consequence, the large current enhances the decay of the voltage/current waveforms because the strong field originated from the large current facilitates the streamer branching and the discharge propagation. ${ }^{11,12)}$ In other words, the decay of the waveforms is essentially influenced by the resistance of water which varies by the velocity of discharge and the amount of the discharge branching. The relation between FWHM of the current and variation of resistance of water is explained by the simplified equivalent circuit, as shown in Fig. 5. The circuit consists of the capacitor of the pulsed power circuit, two gap switches, the cathode fall voltage, and the variable resistance of water $R(t)$. Provided that the resistance of the plasma was neglected owing to the quite small value compared to the $R(t)$. The decay of the current is briefly explained by a time constant $C R(t)$ because the increase rate of the discharge region influenced by the discharge velocity and the amount of the discharge branching leads to the reduction rate of the $R(t)$. Therefore, the variation of $R(t)$ has a significant effect on the FWHM of the current because of the constant value of $C$.

\subsection{Identification of the species in plasma immediately below the needle electrode}

Typical optical emission spectra of the pulsed surface discharge by applying $10 \mathrm{kV}$ under the different water depth (2 and $10 \mathrm{~mm}$ ) are shown in Figs. 6 (a) and (b). The observed atomic and molecular spectra in common through whole experiments were $\mathrm{H}_{\alpha}, \mathrm{H}_{\beta}, \mathrm{O}, \mathrm{N}, \mathrm{N}_{2}$ $(C-B)$, second positive system, and $\mathrm{OH}(A-X)$, which are well observed in the other studies. ${ }^{16,22,23)}$ On the other hand, the ionic spectra $\mathrm{N}^{+}$which have not been observed from the surface discharge on water were observed under the water depth of $2 \mathrm{~mm}$, as shown in Fig. 6 (a). The plasma is supposed to be a high ionization state because the current immediately below the needle is extremely concentrated. The observations of the $\mathrm{N}^{+}$under atmospheric air plasma generated by laser ablation technique and pulsed power are reported in the literature. ${ }^{24,25)}$ The $\mathrm{N}^{+}$is used to verify the local thermodynamic equilibrium (LTE) of 
the plasma in Sect. 3.3.

\subsection{Plasma temperature and validation of local thermodynamic equilibrium}

In general, LTE state in plasma is validated by following McWhirter criterion ${ }^{24)}$

$$
n_{e}>1.6 \times 10^{12} T^{1 / 2}(\Delta E)^{3},
$$

where $n_{\mathrm{e}}$ is the measured electron density in $\mathrm{cm}^{-3}, T$ is the electron temperature in $\mathrm{K}$, and $\Delta E$ is the difference in the energies between the upper and lower states in $\mathrm{eV}$.

Here, an ion excitation temperature $T_{\mathrm{ex}}$ was assigned to (1) as the electron temperature $T$ because $T_{\mathrm{ex}}$ is a good estimate of the $T$ as opposed to an excitation temperature of the atom. ${ }^{26)}$ According to the literature, the excitation temperature of atoms is different from the electron temperature because the distribution function of the excitation state of atoms is influenced by the radiative recombination of ions. The Boltzmann plot analysis, which is a well-known estimation method of $T_{\mathrm{ex}}$, is expressed as follows

$$
\ln \frac{I_{k i} \lambda}{g_{k} A_{k i}}=C-\frac{E_{k}}{k_{B} T_{e x}}
$$

where $I_{\mathrm{ki}}$ is the emissivity in $\mathrm{Wm}^{-3} \mathrm{sr}^{-1}, \lambda$ is the wavelength in $\mathrm{nm}, g_{\mathrm{k}}$ is the statistical weight of the upper level, $A_{\mathrm{ki}}$ is the Einstein transition probability, $E_{\mathrm{k}}$ is the energy of the upper level, $k_{\mathrm{B}}$ is the Boltzmann constant, and $C=\ln \left(N_{\mathrm{k}} h c / 4 \pi Z(T)\right)\left(N_{\mathrm{k}}\right.$ is the atomic density of upper level, $h$ is the Planck's constant, $c$ is the velocity of light, and $Z(T)$ is the partition function). The gradient value of the negative slope $\left(\ln \left(I_{\mathrm{ki}} \lambda / g_{\mathrm{k}} A_{\mathrm{ki}}\right)\right.$ versus $\left.E_{\mathrm{k}} / k_{\mathrm{B}} T_{\mathrm{ex}}\right)$ indicates $T_{\mathrm{ex}}$. Figure 7 shows an example of the Boltzmann plots of $\mathrm{N}^{+}\left(T_{\mathrm{ex}}=30200 \mathrm{~K}\right)$. The selected four $\mathrm{N}^{+}$ lines for Boltzmann plots are summarized in Table I. ${ }^{27)}$ Figure 8 shows electron temperature as a function of the applied voltage. The error range indicates standard deviation. The $T_{\mathrm{ex}}$ increases with increasing the applied voltage.

The $n_{\mathrm{e}}$ was estimated by a spectral broadening of $H_{\alpha}$ to validate the LTE using the Eq. (1). The broadening is normally fitted by Voigt function, which is a convolution function of Gaussian (Doppler and instrumental) and Lorentzian (Stark and Van der Waals) broadenings. The Doppler broadening $\Delta \lambda_{\mathrm{D}}$ is expressed as follows

$$
\Delta \lambda_{D}=7.16 \times 10^{-7} \lambda \sqrt{T_{g} / M},
$$

where the $\lambda$ is the wavelength in $\mathrm{nm}$, the $T_{\mathrm{g}}$ is the gas temperature in $\mathrm{K}$, and the $M$ is the atomic mass in $\mathrm{u}$ (unified atomic mass unit). In this study, the Doppler broadening of $\mathrm{H}_{\alpha}$ was $\Delta \lambda_{\mathrm{D}}=0.081 \mathrm{~nm}$ even for $T_{\mathrm{g}}=30200 \mathrm{~K}$. On the other hand, the instrumental broadening $\Delta \lambda_{\mathrm{I}}$ was approximately $1 \mathrm{~nm}$. The FWHM of the Gaussian function $\Delta \lambda_{\mathrm{G}}$ is defined as follows 


$$
\Delta \lambda_{G}=\sqrt{\Delta \lambda_{D}^{2}+\Delta \lambda_{I}^{2}}
$$

The $\Delta \lambda_{\mathrm{D}}$ can be neglected under this experimental condition because the calculated $\Delta \lambda_{\mathrm{G}}$ was nearly equal to $\Delta \lambda_{\mathrm{I}}(1 \mathrm{~nm})$.

The Van der Waals broadening (in $\mathrm{nm}$ ) is

$$
\Delta \lambda_{v d \text { Waals }}=A \frac{p}{\left(\frac{T g}{300}\right)^{0.7}}
$$

where $p$ is the pressure in bar, $T_{\mathrm{g}}$ is the gas temperature in $\mathrm{K}$, and $A$ is the case of a $\mathrm{N}_{2}$ perturber equal to 0.10 for $\mathrm{H}_{\alpha .}{ }^{25)}$ As the $T_{\mathrm{g}}$ is in the ranging from $30000-50000 \mathrm{~K}$, the contribution of the $\Delta \lambda_{\mathrm{vd}}$ Waals is extremely small compared to the total line width. The assigned $T_{\mathrm{g}}$ to the Eq. (5) is relatively high as a translational temperature; however, the assigned temperature is not irrelevance value because a pulsed arc discharge plasma in dryair with tens of thousands of kelvins was simulated under atmospheric pressure. ${ }^{28)}$ Therefore, the Lorentzian broadening $\Delta \lambda_{\mathrm{L}}$ is approximated by Stark broadening $\Delta \lambda_{\mathrm{s}}$ in this study. The $\Delta \lambda_{\mathrm{s}}$ was obtained by fitting the Voigt function convoluted by Gaussian and Lorentzian broadening to the experimental profile of the $\mathrm{H}_{\alpha}$, as shown in Fig. 9. As a consequence, the $n_{\mathrm{e}}$ in $\mathrm{cm}^{-3}$ is estimated by the following equation ${ }^{29)}$

$$
n_{e}=8.02 \times 10^{12}\left(\frac{\Delta \lambda_{S}}{\alpha}\right)^{3 / 2},
$$

where the $\Delta \lambda_{\mathrm{s}}$ is the Full Width at Half Maximum of the Stark broadening in angstroms and the $\alpha$ is the reduced wavelength in angstroms. The variable number $\alpha$ is tabulated in the literature. ${ }^{30)}$

Figure 10 shows a comparison between the estimated $n_{\mathrm{e}}$ from $\mathrm{H}_{\alpha}$ and electron density calculated by McWhirter criterion from the Eq. (1). Under the experimental condition ranging from 10 to $20 \mathrm{kV}$ satisfy the LTE because the $n_{\mathrm{e}}$ is larger than that of the McWhirter criterion. The plasma immediate below the needle electrode is LTE condition whereas the propagating discharge channel along the water surface does not necessarily correspond to the LTE. The plasma condition at the propagating surface discharge is supposed to be nonLTE. P. Hoffer et al. reported the rotational and vibrational temperature of the surface discharge on water estimated by $\mathrm{N}_{2} 2^{\text {nd }}$ positive system as a function of distance from the needle electrode. ${ }^{22)}$ According to the literature, the significant difference between vibrational and rotational temperatures appears; the vibrational temperature is approximately $3000 \mathrm{~K}$ and the rotational temperature is approximately $750 \mathrm{~K}$. Consequently, the plasma condition of the pulsed surface discharge changes from place to place. Figure 11 shows a rough sketch of the pulsed surface discharge on water with supposed discharge phase. As stated above, 
the discharge plasma at immediately below the needle electrode is LTE state and is supposed to be like a transient arc plasma. The discharge developing along the water surface is a nonLTE state. $^{22)}$

Under the $2 \mathrm{~mm}$ water depth, the $\mathrm{N}^{+}$was detected and the resulting electron temperature was above $30000 \mathrm{~K}$ (see Fig. 8). Here, a discussion arises regarding the validation of LTE under the undetected $\mathrm{N}^{+}$condition as shown in Fig. 6 (b) (water depth of $10 \mathrm{~mm}$ and $10 \mathrm{kV}$ ). The estimation of electron temperature is difficult unless $\mathrm{N}^{+}$is observed. However, since the $\mathrm{N}^{+}$was not detected for the $10 \mathrm{~mm}$ water depth, the electron temperature for the $10 \mathrm{~mm}$ water depth was below $30000 \mathrm{~K}$, which is the highest value expected for water depth of 10 $\mathrm{mm}$. Therefore, the electron temperature of $30000 \mathrm{~K}$ imposes the most severe McWhirter criterion on the electron density required for the LTE establishment under the $10 \mathrm{~mm}$ water depth. The electron density calculated by McWhirter criterion at the electron temperature of $30000 \mathrm{~K}$ was $4.2 \times 10^{15} \mathrm{~cm}^{-3}$, which was lower than that measured by $\mathrm{H}_{\alpha}\left(9.0 \times 10^{15} \mathrm{~cm}^{-3}\right)$. As a consequence, the establishment condition of LTE was fulfilled at water depth of $10 \mathrm{~mm}$. However, the detailed validation should be done in the future.

\section{Conclusions}

This study deals with the plasma behavior of the pulsed surface discharge on water which dramatically changes even if the applied voltage increases simply. In addition, the local thermodynamic equilibrium (LTE) of the plasma was verified on the basis of McWhirter criterion. The obtained results are summarized as follows.

1. The peak value of the current linearly increased with applied voltage whereas the pulse width of the current decreased exponentially. The cause of the decrease of the pulse width of current is explained by the time constant $C R(t)$ ( $C$ is the capacitance of the pulsed power generator and $R(t)$ is variable resistance of water). The decrease of $R(t)$ is accelerated by the increase of the discharge contact area owing to the increase of the discharge velocity and of the amount of the discharge branching. Consequently, the increase in the peak of the current induces the decrease in FWHM of the current.

2. The discussions of the spectroscopic measurement are centered on the observation of the ionic spectrum of $\mathrm{N}^{+}$. Although the $\mathrm{N}^{+}$is generally not observed from the surface discharge on water, the $\mathrm{N}^{+}$was observed at the immediately below the needle electrode in the case of the relatively thin water depth $(2 \mathrm{~mm})$. The observation of the $\mathrm{N}^{+}$is attributed to high ionization rate. Furthermore, this observation enables the estimation of the electron temperature by Boltzmann plot to be utilized because the excitation 
temperature of $\mathrm{N}^{+}$gives a good estimation of the electron temperature.

3. The plasma state immediately below the needle electrode is estimated LTE because the estimated electron densities ranging from 10 to $20 \mathrm{kV}$ are larger than those of the McWhirter criterion. On the other hand, propagated surface discharge separated from the needle electrode is supposed to be non-LTE.

\section{Acknowledgments}

This work was partially supported by JSPS KAKENHI Grant-in-Aid for Scientific Research (C) Grant Number 19K04329. 


\section{References}

1) P. J. Bruggeman, M. J. Kushner, B. R. Locke, J. G. E. Gardeniers, W. G. Graham, D. B. Graves, R. C. H. M. Hofman-Caris, D. Maric, J. P. Reid, E. Ceriani, D. Fernandez Rivas, J. E. Foster, S. C. Garrick, Y. Gorbanev, S. Hamaguchi, F. Iza, H. Jablonowski, E. Klimova, J. Kolb, F. Krcma, P. Lukes, Z. MacHala, I. Marinov, D. Mariotti, S. Mededovic Thagard, D. Minakata, E. C. Neyts, J. Pawlat, Z. L. Petrovic, R. Pflieger, S. Reuter, D. C. Schram, S. Schröter, M. Shiraiwa, B. Tarabová, P. A. Tsai, J. R. R. Verlet, T. Von Woedtke, K. R. Wilson, K. Yasui and G. Zvereva, Plasma Sources Sci. Technol. 25, 053002 (2016).

2) K. Takahashi, R. Konno, N. Satta and K. Takaki, IEEE Trans. Plasma Sci. 46, 663 (2018).

3) P. Lukes, E. Dolezalova, I. Sisrova and M. Clupek, Plasma Sources Sci. Technol. 23, 015019 (2014).

4) K. Satoh, S. J. MacGregor, J. G. Anderson, G. A. Woolsey and R. A. Fouracre, Jpn. J. Appl. Phys. 46, 1137 (2007).

5) Y. Hayashi, S. Machmudah, N. Takada, H. Kanda, K. Sasaki, M. Goto and Wahyudiono, Jpn. J. Appl. Phys. 53, 010212 (2014).

6) Wahyudiono, H. Watanabe, S. Machmudah, T. Kiyan, M. Sasaki, H. Akiyama and M. Goto, Chem. Eng. Process. Process Intensif. 61, 51 (2012).

7) Y. Hirano, R. Miyanomae, M. Sasaki, A. T. Quitain, T. Kida and S. Okubayashi, IEEE Trans. Plasma Sci. 44, 211 (2016).

8) P. Lukes, M. Clupek, V. Babicky, V. Janda and P. Sunka, J. Phys. D: Appl. Phys. 38, 409 (2005).

9) R. J. Wandell, H. Wang, K. Tachibana, B. Makled and B. R. Locke, Plasma Process. Polym. 15, 1 (2018).

10) K. C. Hsieh, R. J. Wandell, S. Bresch and B. R. Locke, Plasma Process. Polym. 14, (2017).

11) T. Furusato, Y. Yamamoto, T. Sakamoto, K. Oura, Y. Matsuda and T. Yamashita, IEEE Trans. Dielectr. Electr. Insul. 26, 439 (2019).

12) T. Furusato, D. Obata, Y. Yota and Y. Takahiko, IEEE Trans. Plasma Sci. 46, 2079 (2018).

13) P. Lukes, M. Clupek and V. Babicky, IEEE Trans. Plasma Sci. 39, 2644 (2011).

14) K. Yoshihara, Ruma, S. H. R. Hosseini, T. Sakugawa and H. Akiyama, IEEE Trans. Plasma Sci. 42, 3226 (2014). 
15) M. Sato, T. Tokutake, T. Ohshima and A. T. Sugiarto, IEEE Trans. Ind. Appl. 44, 1397 (2008).

16) P. Bruggeman, J. L. Walsh, D. C. Schram, C. Leys and M. G. Kong, Plasma Sources Sci. Technol. 18, 045023 (2009).

17) S. Kanazawa, H. Kawano, S. Watanabe, T. Furuki, S. Akamine, R. Ichiki, T. Ohkubo, M. Kocik and J. Mizeraczyk, Plasma Sources Sci. Technol. 20, 034010 (2011).

18) P. Lukes and B. R. Locke, J. Phys. D: Appl. Phys. 38, 4074 (2005).

19) N. S. Midi, R. Ohyama and S. Yamaguchi, J. Electrostat. 71, 823 (2013).

20) Y. Akishev, V. Karalnik, M. Medvedev, A. Petryakov, A. Shafikov and N. Trushkin, Plasma Sources Sci. Technol. 26, 025004 (2017).

21) T. Furusato, T. Sadamatsu, Y. Matsuda and T. Yamashita, IEEE Trans. Plasma Sci. 45, 711 (2017).

22) P. Hoffer, Y. Sugiyama, S. H. R. Hosseini, H. Akiyama, P. Lukes and M. Akiyama, J. Phys. D: Appl. Phys. 49, 415202 (2016).

23) S. Wang, Y. De-xheng, W. Wenchun and F. Zhi, J. Appl. Phys. 125, 043304 (2019).

24) J. J. Camacho, M. Santos, L. Díaz, L. J. Juan and J. M. L. Poyato, Appl. Phys. A Mater. Sci. Process. 99, 159 (2010).

25) R. M. Van Der Horst, T. Verreycken, E. M. Van Veldhuizen and P. J. Bruggeman, J. Phys. D: Appl. Phys. 45, 345201 (2012).

26) A. Lo, A. Cessou, C. Lacour, B. Lecordier, P. Boubert, D. A. Xu, C. O. Laux and P. Vervisch, Plasma Sources Sci. Technol. 26, 045012 (2017).

27) W. L. Wiese, M. W. Smith and B. M. Glennon, Atomic transition probabilities: volume 1 - hydrogen through neon: critical data compilation (National Bureau of Standards, 1966).

28) Y. Tanaka, T. Michishita and Y. Uesugi, Plasma Sources Sci. Technol. 14, 134 (2005).

29) J. Ashkenazy, R. Kipper and M. Caner, Phys. Rev. A 43, 5568 (1991).

30) H. R. Griem, Spectral line broadening by plasmas (Academic press, New York and London, 1974). 


\section{Figure Captions}

Fig. 1. Illustrations of the experimental setup. (a) Experimental circuit. (b) Spectroscopic measurement system.

Fig. 2. Top view of the single-shot positive pulsed surface discharge on water $(20 \mathrm{kV}$ and water depth: $2 \mathrm{~mm}$ ).

Fig. 3. Typical voltage and current waveforms ( $20 \mathrm{kV}$ and water depth: $2 \mathrm{~mm})$.

Fig. 4. The peak and FWHM of the discharge current as a function of an applied voltage (water depth: $2 \mathrm{~mm}$ ).

Fig. 5. Simplified equivalent circuit of the experimental circuit including surface discharge on water.

Fig. 6. Optical emission spectra of the pulsed surface discharge on water under the applied voltage of $10 \mathrm{kV}$; (a) water depth: $2 \mathrm{~mm}$ and (b) water depth: $10 \mathrm{~mm}$.

Fig. 7. Boltzmann plots from $\mathrm{N}^{+}$lines $(10 \mathrm{kV}$ and water depth: $2 \mathrm{~mm})$.

Fig. 8. The plasma temperature as a function of the applied voltage (water depth: $2 \mathrm{~mm}$ ).

Fig. 9. The profile of $\mathrm{H}_{\alpha}$ and the theoretical profile based on Voigt function (water depth: 2 $\mathrm{mm})$.

Fig. 10. The electron density estimated by broadening of the $\mathrm{H}_{\alpha}$ and McWhirter criterion (water depth: $2 \mathrm{~mm}$ ).

Fig. 11. An illustration of the pulsed surface discharge on water and its discharge phase. 
Table I. The spectroscopic constants of four $\mathrm{N}^{+}$lines used for the analysis of Boltzmann plot, where $\lambda$ is the wavelength of the line, $A_{\mathrm{ki}}$ is the transition probability, $g_{\mathrm{k}}$ is the statistical weight of the upper level, $E_{\mathrm{k}}$ is the energy of upper level, and $E_{\mathrm{i}}$ is the energy of the lower level. ${ }^{27)}$

\begin{tabular}{ccccc}
\hline$\lambda, \mathrm{nm}$ & $A_{\mathrm{ki}, \mathrm{s}^{-1}}$ & $E_{\mathrm{k}, \mathrm{eV}}$ & $E_{\mathrm{i}, \mathrm{eV}}$ & $g_{\mathrm{k}}$ \\
\hline 500.45 & $122 \times 10^{6}$ & 23.135 & 20.658 & 21 \\
553.74 & $560 \times 10^{5}$ & 27.739 & 25.501 & 25 \\
567.94 & $560 \times 10^{5}$ & 20.658 & 18.475 & 15 \\
593.85 & $565 \times 10^{5}$ & 23.244 & 21.156 & 15 \\
\hline
\end{tabular}




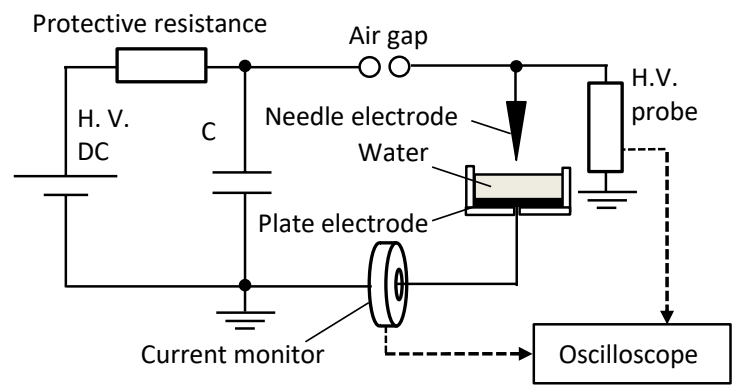

(a)

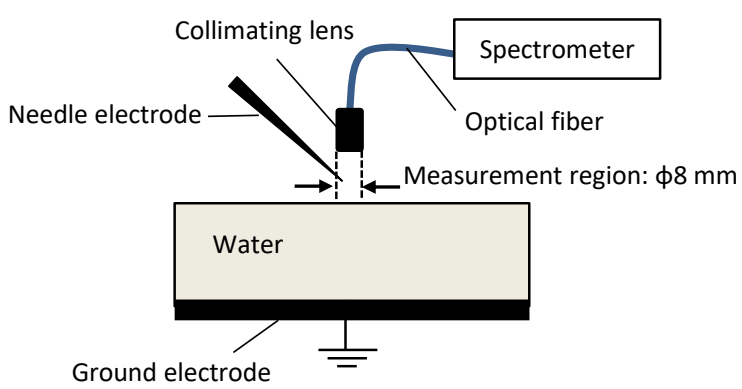

(b)

Fig. 1.

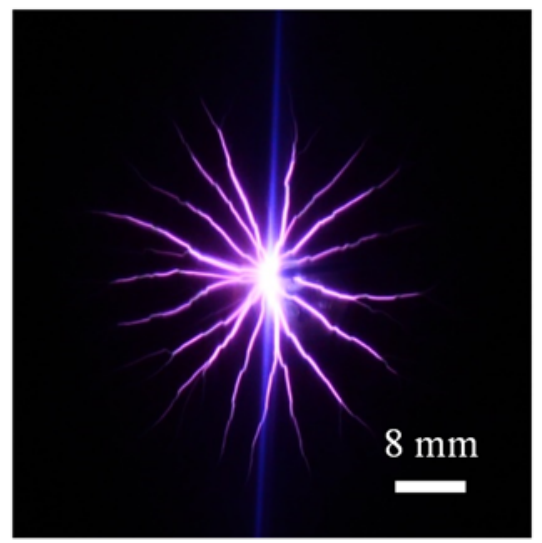

Fig. 2. 


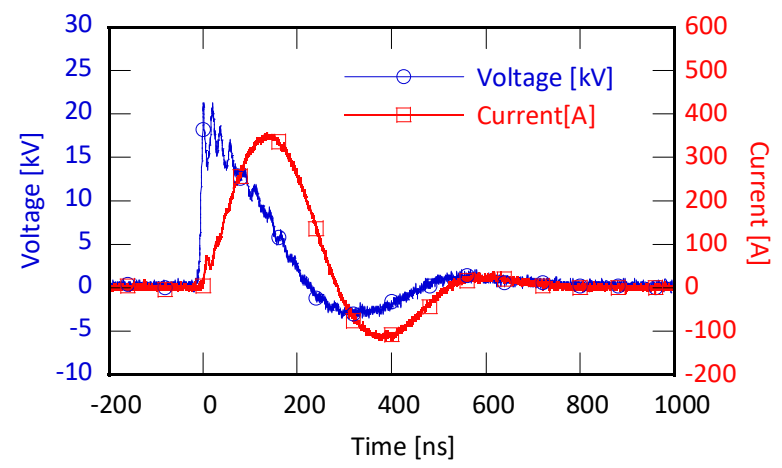

Fig. 3.

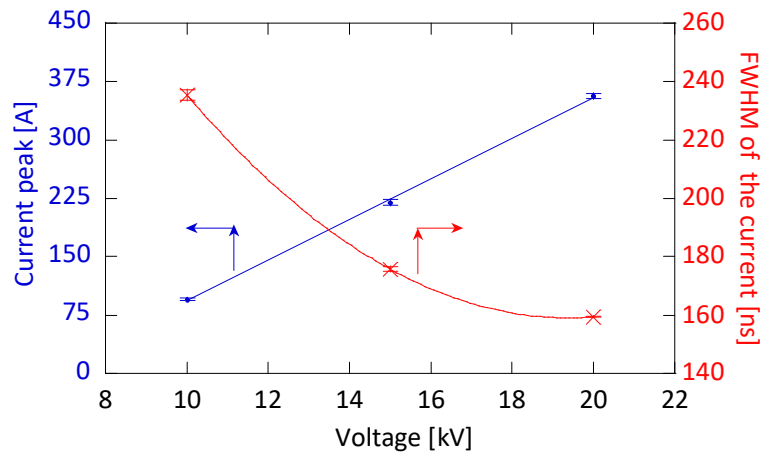

Fig. 4. 


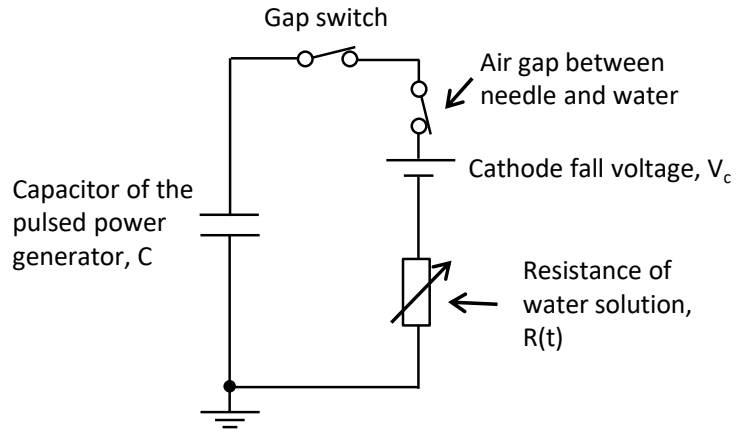

Fig. 5.

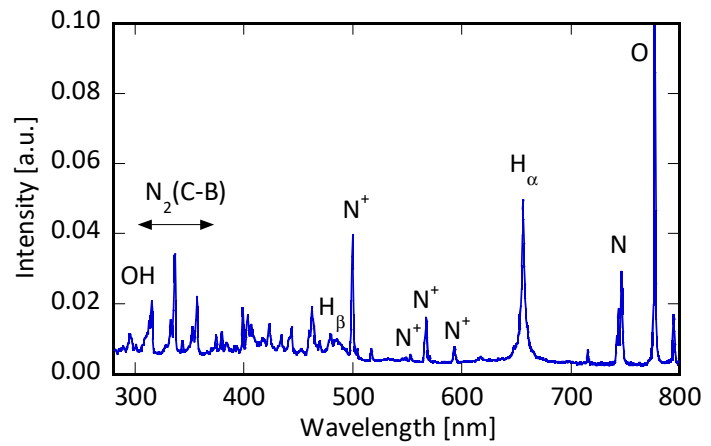

(a)

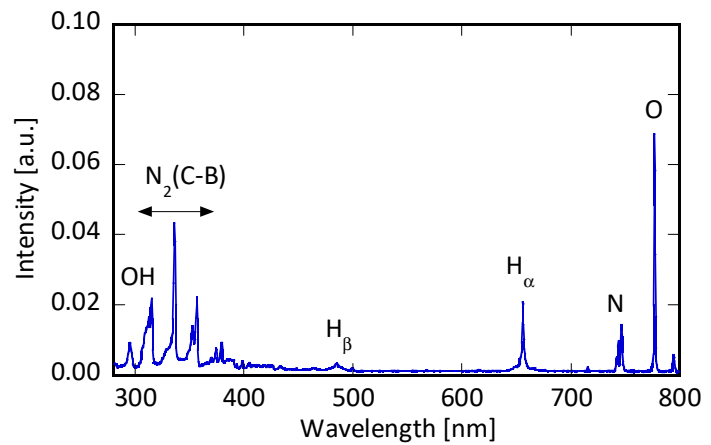

(b)

Fig. 6. 


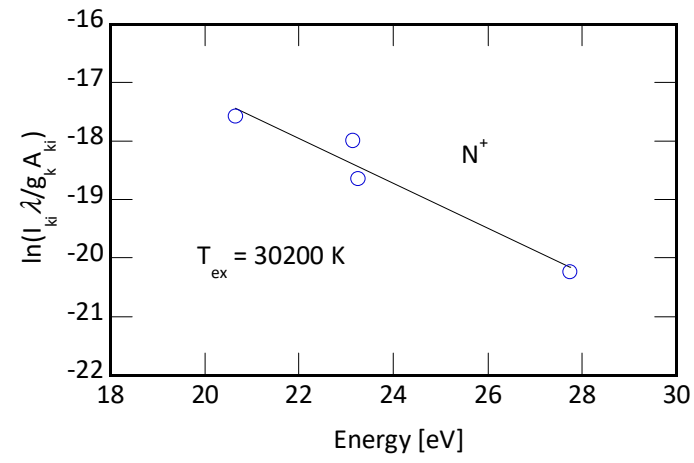

Fig. 7.

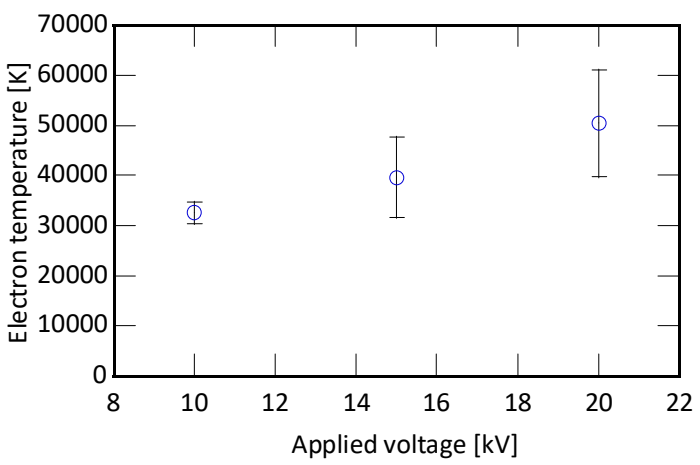

Fig. 8.

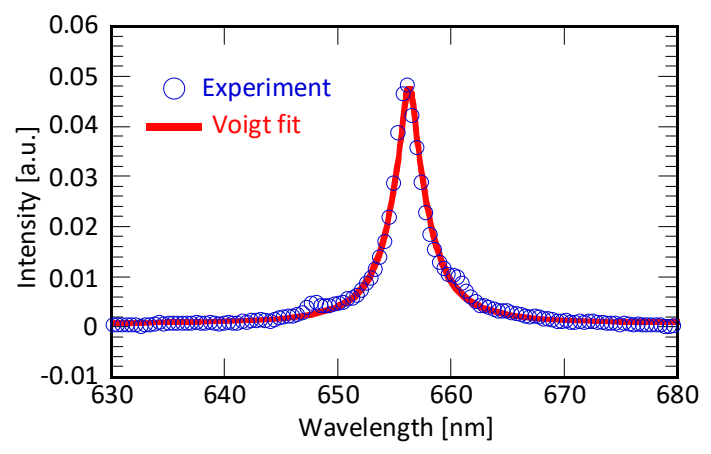

Fig. 9. 


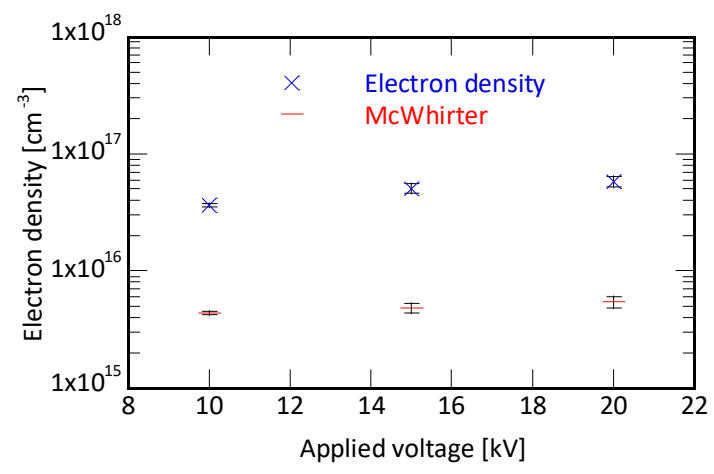

Fig. 10.

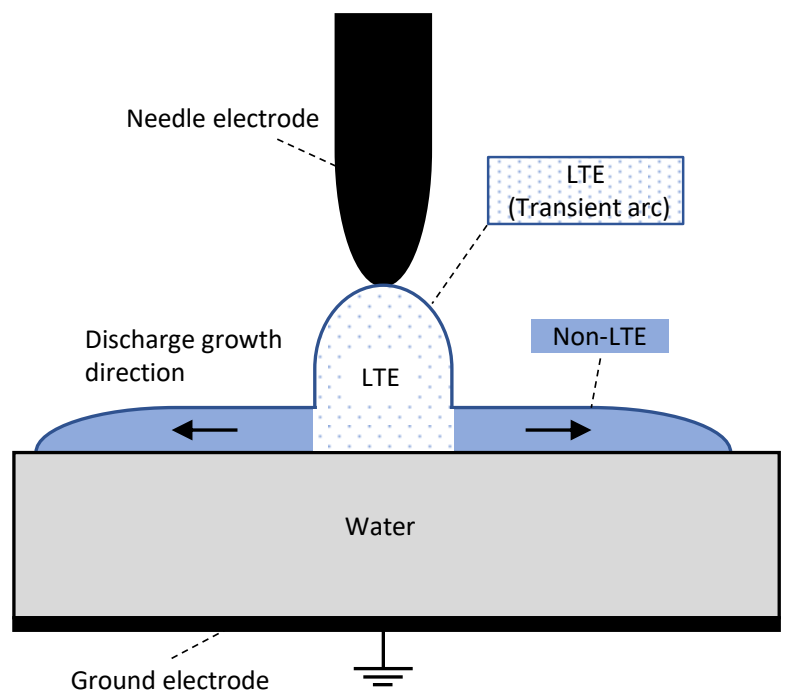

Fig. 11. 